Josaphat C. Tam

\title{
Apprehension of Jesus in the Gospel of John
}

[Das Erkennen Jesu im Johannesevangelium.]

Veröffentlicht auf Englisch.

Josaphat C. Tam erörtert das Konzept des »Erkennens Jesu« im Johannesevangelium, indem er darauf fokussiert, wie Johannes

JOSAPHAT C. TAM

Apprehension of Jesus in the Gospel of John

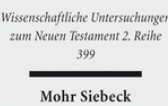
die Begriffe des Sehens, Hörens, Wissens, Bezeugens, Erinnerns und Glaubens verwendet. Der Autor leistet damit einen Beitrag zu einem besseren Verständnis dieses Konzepts sowie Johannes' Überzeugungsstrategien, indem er vier Phasen des »Verstehens Jesu« entlang der Handlung abgrenzt. Auf dieser Grundlage postuliert der Autor eine vierfache Wirkabsicht des Johannes auf seine Leser: Erstens beabsichtigt Johannes, sowohl bei Gläubigen wie auch bei Ungläubigen Glauben zu schaffen. Zweitens erinnert Johannes seine Adressaten geschickt an die Bedeutung der »Gegenwärtigkeit« Jesu als eines lebendigen, allwissenden und göttlichen Seins. Drittens wird das vergangene, erzählte »Sehen« und »Hören« im Evangelium in Verbindung gebracht mit dem Lesen des glaubwürdigen Zeugnisses des Johannes in der Gegenwart. Schließlich wird der (Un)Glaube der Leser den herausfordernden Möglichkeiten ausgesetzt, die sich in der Begegnung mit dem erzählten Jesus auftun.

Josaphat C. Tam 2003 MDiv at Evangel Seminary, Hong Kong; 2008 ThM (NT) at Trinity Evangelical Divinity School, Illinois, US; 2015 PhD at New College, University of Edinburgh, Scotland; currently Associate Professor at Evangel Seminary, Hong Kong. https://orcid.org/0000-0001-8657-4563 https://orcid.org/0000-0001-8657-4563

2015. XVII, 265 Seiten. WUNT II 399

ISBN 978-3-16-154066-0

DOI 10.1628/978-3-16-154066-0

eBook PDF $104,00 €$

ISBN 978-3-16-154065-3

fadengeheftete Broschur 104,00€

Jetzt bestellen:

https://mohrsiebeck.com/buch/apprehension-of-jesus-in-the-gospel-of-john-9783161540660?no_cache=1

order@mohrsiebeck.com

Telefon: +49 (0)7071-923-17

Telefax: +49 (0)7071-51104 